rumson

glyndŵn

Glyndŵr University

Glyndŵr University Research Online

$1-1-2009$

\title{
Molecular interactions of plant and algal polysaccharides
}

Peter A. Williams

Glyndwr University, p.a.williams@glyndwr.ac.uk

Follow this and additional works at: http://epubs.glyndwr.ac.uk/cwsp

Part of the Polymer Chemistry Commons

(c) 2009 Springer This version of the article is the authors final draft post-refereeing. The article was published in the Journal of Structural Chemistry published by Springer in 2009. The original publication is available at http://www.springerlink.com

\section{Recommended Citation}

Williams, P. A. (2009) 'Molecular interactions of plant and algal polysaccharides'. Structural Chemistry, 20(2), 299-308.

This Article is brought to you for free and open access by the Materials Science at Glyndŵr University Research Online. It has been accepted for inclusion in Centre for Water Soluble Polymers by an authorized administrator of Glyndŵr University Research Online. For more information, please contact d.jepson@glyndwr.ac.uk. 


\title{
Molecular interactions of plant and algal polysaccharides
}

\author{
Peter A. Williams \\ Centre for Water Soluble Polymers, \\ Glyndwr University, Plas Coch, Mold Road, Wrexham, \\ LL11 2AW, United Kingdom \\ Tel: $\quad+44(1978) 293083$ \\ Email : williamspa@glyndwr.ac.uk
}

\begin{abstract}
This paper gives an overview of the interaction in solution of certain plant and algal polysaccharides with cations and also of their interaction in admixture with other polysaccharides and proteins. The mechanism of gelation of pectin and alginate in the presence of calcium ions is discussed together with the specific binding of potassium ions to kappa carrageenan and its influence on the coli-helix transition. The associative and segregative phase behaviour that is encountered in aqueous solutions of mixed polysaccharide systems is considered together with the formation of soluble and insoluble complexes in mixtures of polysaccharides and proteins.
\end{abstract}




\section{Introduction}

The cell wall of most flowering plants consists of a highly hydrated polymeric matrix which contains approximately $40 \%$ polymer and $60 \%$ water [1]. The mechanical strength is provided by a network of cellulose microfibrils which are interconnected typically by adsorbed xyloglucan chains although other polysaccharides such as glucuronoarabinoxylans, gluco- and galactoglucomannans, galactomannans and $\beta$ glucans are also found in lesser amounts. Structural proteins, notably the hydroxyproline-rich glycoprotein extensin, are also believed to be involved in crosslinking the microfibrils. The cellulose - xyloglucan framework is embedded in a matrix of pectin, which is a heteropolysaccharide consisting mainly of galacturonic acid together with a lesser proportion of neutral sugars which are present mainly as sidechains. It accounts for about one third of the total mass of the cell wall. The pectin molecules influence the cell wall porosity and modulate the $\mathrm{pH}$ and ion balance thus influencing ion transport. They also serve as recognition molecules that signal developmental responses to other organisms.

The cell walls of algae have many of the structural features of higher plants although the proportion of fibrous material is usually lower while the matrix and intracellular material is greater and they commonly excrete polysaccharide material onto the outer surface. Algae require a more flexible structure compared to land plants so that they can accommodate the varying stresses of currents and wave motion and are found to contain many different polysaccharides [2]. Agar, for example, which consists of neutral and charged polygalactans is the major component in the cell wall of Gracilaria verrucosa species. It has a minor role in controlling ion exchange between the medium and cytoplasm but functions mainly to control the physical and mechanical properties 
and is involved in cell expansion [3]. Other seaweed polysaccharides include the carrageenans, furcelleran, alginates and fucoidin.

This paper provides an overview of the interactions of pectin, alginate and carrageenan with cations which lead to junction zone formation and gelation. It also considers interactions between different polysacharides and between polysaccharides and proteins.

\section{Interaction of anionic polysaccharides with cations}

\section{Pectin and alginate}

Pectins are heteropolysaccharides which consist of mainly galacturonic acid with a small proportion of neutral sugars present as side chains [4-7]. Commercial pectins are obtained from apple pomace or the peel of citrus fruits particularly lemons or limes. Most pectin is produced by extraction in hot aqueous mineral acid followed by precipitation with alcohol. The principal pectin component consists of linear chains of $(1,4)-\alpha$-galacturonic acid residues up to $80 \%$ of which occur as the methyl ester together with up to $4 \%(1,2)$ - $\alpha$-rhamnopyranose units which are distributed along the chain. Branched side chains consisting of L-arabinose, D-galactose and D-xylose (10$15 \%)$ are linked to the galacturonic acid backbone through the rhamnose units. This is illustrated schematically in Figure 1 which shows linear 'smooth regions' (galacturonic acid chains) and the 'hairy regions' (branched side chains consisting of mainly neutral sugars). Pectin is soluble in water and is most stable at $\mathrm{pH}$ 's of $\sim 3-4$. Above and below this value hydrolysis may occur. Pectin with a high degree of esterification (DE60-75\%) forms gels at low water activity, for example, at high soluble solids content (typically $50-75 \%$ sugar) and at $\mathrm{pH} \sim 3.5$ over a period of time. Molecular association is believed to be as a consequence of hydrophobic association between ester groups coupled with 
intermolecular hydrogen bonding between hydroxyl groups on the galacturonan backbone. The gels formed are not thermoreversible. At low degree of esterification, (DE typically $20-40 \%$ ) gelation is brought about by the addition of divalent cations. A high soluble solids content and low $\mathrm{pH}$ are not necessary for gelation to occur. Gelation is rapid and is usually thermoreversible.

Alginates occur as a structural component in marine brown algae (Phaeophyceae) and consist of linear chains of $(1,4)$ - linked $\beta$-D-mannuronate $(M)$ and $\alpha$-L-guluronate $(G)$ residues $[8,9]$. The residues occur in blocks of separate (M or $G$ ) or mixed (MG) sequences and the overall composition and arrangement varies with the seaweed source. Macrocystis pyriferia and Ascophyllum nodosum have a high mannuronic acid content (61\% and $65 \%$ respectively), whereas Laminaria hyperborea has a high guluronic acid content (69\%). Sodium alginate dissolves readily in water to form viscous solutions and thermally irreversible gels are formed in the presence of divalent cations.

The cation induced gelation of alginate and pectin is widely attributed to the association of sequences of guluronate and galacturonate residues for alginate and pectin respectively [10-12]. These sugars are linked diaxially along the chain, whereas the mannuronate residues in alginate are linked equatorially. This is illustrated in Figure 2 which shows the disaccharide repeating units for four different acidic polysaccharides. Galacturonan and guluronan give rise to a buckled chain structure while glucuronan and mannuronan give rise to linear ribbon-like chains. Computer modelling has shown that guluronate chains have two or three fold screw symmetry which gives rise to four -oxygen coordination involving $O(6)$ and in most cases $O(5)$ with $\mathrm{O}(2)$ and $\mathrm{O}(3)$ in the adjacent sugar in the direction of the non-reducing end. 
Fewer coordination possibilities exist for galacturonate with only three oxygen atoms thus explaining why guluronate forms stronger complexes. In the presence of divalent ions interchain association occurs by dimerisation of chain sequences with divalent cations and is commonly referred to as the 'egg - box' model [10] (Figure 3). The mannuronate residues in alginate give sites with both two and three-fold symmetry but the equatorial linkages lead to a much flatter structure which can less readily accommodate the cations.

Recent molecular modelling studies of the interaction of calcium ions with alginate and pectin also found that for $\alpha(1,4)$ linked chains there is high stereo-specificity for calcium ions while in contrast for $\beta(1,4)$ linked chains there are no specific calcium binding sites and the interaction is purely electrostatic [13, 14]. Furthermore, polymer chain stiffness which will influence junction zone formation increases in the order mannuronic < galacturonic < guluronic. Although the modelling studies concluded that the 'egg box model' adequately describes the dimersiation of guluronate this was not the case for galacturonate association.

Other workers have shown that alginate consisting almost entirely of mannuronate can also form gels hence casting some doubt on the specific nature of the 'egg-box' model [15]. Studies on the binding of $\mathrm{Mn}^{2+}$ ions using ${ }^{13} \mathrm{C}$ NMR spectroscopy with pure mannuronate and guluronate blocks have provided experimental evidence of the presence of specific binding sites along the alginate chain [15]. For mannuronate, association was found to be limited to the C6 and to a lesser extent the C5 positions while for guluronate, an additional interaction was observed at $\mathrm{C} 1$. This confirms that the interaction with mannuronate is primarily electrostatic while for guluronate, in addition to purely electrostatic interaction, the $\mathrm{Mn}^{2+}$ ion may also reside in the gap between two guluronate residues with a tendency towards the oxygen atom between positions 5 and 1 . It has also been suggested that guluronate residues with a 
mannuronate attached to the $\mathrm{C} 1$ position are much more likely to host $\mathrm{a} \mathrm{Mn}^{2+}$ ion (Figure 4).

We have recently reported on the binding of $\mathrm{Mn}^{2+}$ ions to pectin and alginate using ESR spectroscopy and the binding isotherms are presented in Figure 5 [16]. The curves show that the amount bound ( $\mathrm{mol} \mathrm{Mn}^{2+} / \mathrm{mol} \mathrm{COO}^{-}$) was $0.2,0.2$ and 0.25 for high $M: G$ alginate, low $M: G$ alginate and pectin respectively. This means in effect that the binding process is non - stoichiometric and that at maximum binding there is approximately only one $\mathrm{Mn}^{2+}$ ion for every four carboxylate groups which in fact is consistent with the 'egg box model'. Since the distance between the carboxylate groups on the polymer chains is greater than the hydrated radius of divalent cations we have proposed that the divalent cations interact with a single carboxylate group initially forming a monocomplex. This then leads to creation of a net single positive charge at the carboxylate site and induces crosslinking by interaction with carboxylate groups on other polymer chains. This is schematically represented in Figure 6.

\section{Carrageenan}

Carrageenans are present as structural components in various species of red seaweeds (Rhodophyceae) $[17,18]$. The three main types which are readily available commercially are kappa, iota and lambda. Kappa is obtained from Euchema cottonii species and occurs together with lambda carrageenan in Chondrus crispus. lota carrageenan is obtained from Euchema spinosum. They differ essentially in their degree of sulphation. The carrageenan backbone is based on a disaccharide repeat unit of $\beta-D$ - galactopyranose residues linked through the 1 and 3 positions and $\alpha-$ galactopyranose residues linked through the 1 and 4 positions (Figure 7). For both kappa and iota carrageenan the latter occurs in the 3,6, anhydro form. Kappa carrageenan has a sulphate group at the 4 position of the $\beta-D$ - galactopyranose 
residues while iota carrageenan is sulphated additionally at the $C 2$ position of the $\beta-D$ - galactopyranose residues. Lambda carrageenan is further sulphated and consists of $(1,4)$-linked galactopyranose 2,6 disulphate and (1,3) -linked galactopyranose which are $70 \%$ substituted at the $\mathrm{C} 2$ position. Millane et al undertook X-ray diffraction studies on kappa and iota carrageenan and concluded that they adopt ordered double helical structures in their native state [19]. However, this is not the case for lambda carrageenan. It is assumed that the additional sulphate groups prevent helix formation through steric hindrance or possibly electrostatic repulsion.

The behaviour of these three carrageenan types differs significantly in solution. Lambda carrageenan readily dissolves in water to form viscous solutions at concentrations of $\sim 1 \%$ or more. However, both kappa and iota carrageenans form thermoreversible gels on cooling. The molecules undergo a coil - helix conformational transition and the helices self-associate through hydrogen bonding giving rise to a three dimensional gel structure (Figure 8).

The temperature of the conformational transition increases with increasing electrolyte concentration and varies with the nature of the ions added. In the case of kappa carrageenan, potassium, rubidium and caesium ions have a profound effect compared to other cations and this has been attributed to specific binding to the helical structure [17]. The nature of the binding site is not clear but may involve a number of oxygen atoms within the helix. The specific binding stabilises the helical conformation and as a consequence, the helices form at a higher temperature and lower electrolyte concentration. This ion specificity is not observed for iota carrageenan and the coilhelix transition is promoted only by charge screening effects of the electrolyte present. The binding of cations reduces the effective charge density of the helical chains and hence promotes helix aggregation and the formation of a three dimensional gel structure. The influence of various cations on helix aggregation has been studied using 
Electron Microscopy [20] and has shown that in the presence of potassium ions the carrageenan helices formed stiff superstrands leading to a fine or coarse network structure depending on the potassium concentration. In the presence of sodium ions, however, flexible superstrands were formed whilst in the presence of calcium ions a fine network structure was obtained. Funami et al [21] have recently used AFM to study these systems and found that potassium ions increased chain stiffness while calcium ions mediated crosslinks between strands. The different effects of these cations will have an influence on the mechanical and water binding characteristics of the gel matrix.

\section{Interactions between polysaccharides}

There are many reports in the literature on the interactions in mixed polysaccharide systems in aqueous solution [22, 23]. The various types of behaviour observed are summarised in Figure10.

In many cases there is no associative interaction between the two polymer species. At low total polymer concentrations the polymers will remain as an essentially homogeneous mixture whilst at higher concentrations they will phase separate and form two (usually) liquid layers each enriched in one of the polymers. This is illustrated in Figure 11 which shows phase separation occurring in mixtures of gelatinised sago starch and dextran. The phase diagrams for mixtures of sago starch and the seed galactomannans, guar gum (Cyamopsis tetragonoloba) and locust bean gum (Ceratonia siliqua) are presented in Figure 12 [24]. The lines through the experimental points represent the binodal which separates the 1-phase and 2-phase regions. Mixtures with compositions of galactomannan and starch which occur below the binodal remain as homogeneous solutions whilst mixtures with compositions above the binodal exhibit phase separation. 
In certain cases molecular association between polysaccharide chains can occur [23]. In general this is limited to;

- helical polysaccharides in combination with semi-flexible ribbon-like polymer chains

- oppositely charged polysaccharides

- polysaccharides that associate through cation mediated crosslinking

In the context of possible interactions within the cell wall, systems containing both helical and ribbon-like polysaccharide chains are the most relevant to consider here.

\section{Interactions in systems containing helical and ribbon-like polysaccharide chains}

As noted above, kappa carrageenan forms thermoreversible gels due to association of the helical chains. The gels tend to be fairly opaque and are rather brittle and subject to syneresis. However, when gelation is induced in the presence of konjac mannan or locust bean gum they become optically transparent and more elastic and have a lesser tendency to undergo syneresis. The change in characteristics has been attributed to molecular association between the carrageenan and konjac mannan / locust bean gum $[25,26]$. Konjac mannan is a glucomannan obtained from the tuber of the konjac plant, Amorphophallus konjac and consists of linear ribbon-like chains of $\beta(1,4)$ linked glucose and mannose units with branches of up to 16 sugar residues positioned approximately every 10 sugar residues along the backbone [27]. The mannose to glucose ratio is $\sim 1.6: 1$. As noted above locust bean gum is a galactomannan and also has a ribbon-like conformation consisting of a $\beta(1,4)$ - linked mannose backbone with a galactose residue attached through a $(1,6)$ link approximately every one in four mannose units. The galactose residues, however, are not uniformly distributed along 
the mannan chain and there are 'smooth' regions along the backbone devoid of galactose residues [28]. Studies on the association between konjac mannan or locust bean gum and kappa carrageenan have shown that the interaction occurs only when the carrageenan is in its ordered helical form. It has been proposed that the molecules associate through hydrogen bonding once the ordered structure has formed. In the case of locust bean gum, it is proposed that the interaction occurs through the unsubstituted regions along the locust bean gum chain $[29,30]$. This is endorsed by the fact that guar gum, which has galactose residues positioned on approximately every other mannose unit does not interact. The phenomenon is not just restricted to carrageenan and gluco- / galacto- mannans. It has been shown that association also occurs for other helical polysaccharides, notably agar and xanthan gum (a bacterial cell wall polysaccharide) with other ribbon-like polysaccharides including carboxymethyl cellulose and xylans [23].

We have confirmed that there is an associative interaction between kappa carrageenan and konjac mannan by NMR and ESR spectroscopy and differential scanning calorimetry (DSC) $[25,31]$. The DSC cooling curves obtained for kappa carrageenan in the presence of $50 \mathrm{mM} \mathrm{KCl}$ and varying concentrations of konjac mannan are shown in Figure 13. Kappa carrageenan alone, (curve G), gave an exothermic peak with a mid point transition temperature at $40^{\circ} \mathrm{C}$. The enthalpy associated with the peak is attributed predominantly to the coil - helix conformational transition of the carrageenan molecules and to a lesser extent helix association. For carrageenan - konjac mannan mixtures with carrageenan in excess (curves D,E and F) two peaks were observed, namely at $43.5^{\circ} \mathrm{C}$ and $40^{\circ} \mathrm{C}$. The higher temperature peak corresponds to the coil - helix transition of the carrageenan and subsequent association with konjac mannan, while the lower temperature peak corresponds to the 
coil - helix transition of the excess carrageenan. When the konjac mannan was in excess (curves $A, B$ and $C$ ) the lower temperature peak disappeared since all of the carrageenan present had interacted with the konjac mannan. Similar results have also been reported for kappa carrageenan - locust bean gum mixtures although the enthalpy of the association was considerably less [26]. For such mixtures at low kappa carrageenan concentrations it was proposed that the locust bean gum molecules interact with more than one carrageenan helix forming a bridge and leading network formation (Figure 14).

\section{Polysaccharide - protein interactions}

There has been considerable work undertaken in recent years on the investigation of the phase behaviour of polysaccharide- protein mixtures in solution, however, relatively few have been concerned with systems in which the polysaccharide and protein naturally co-exist, that is, so-called cognate systems $[32,33]$. In the context of the plant cell wall, Sakamoto et al [34] studied the binding of polygalacturonase-inhibiting proteins to polygalacaturonic acid and found that binding increased when the degree of esterification decreased thus suggesting that electrostatic interaction was occurring between the protein and polysaccharide. MacDougall et al investigated the effect of peptides on the gelation of pectin from the tomato cell wall and concluded that non covalent interactions occur and are involved in the attachment of extensin molecules to the pectin matrix and contribute to the structural assembly of the proteins in the cell wall [35].

The studies reported on non - cognate polysaccharide - protein systems in recent years and the general observations made, provide insights into the nature of the interactions and phase behaviour that can occur. It is evident that the behaviour 
observed is influenced by a number of factors including the polysaccharide to protein ratio, the $\mathrm{pH}$ and the ionic strength. Association readily occurs when the polysaccharide and protein have opposite charge. The electrostatic complexes produced may be insoluble in the form of coacervates or precipitates or they may be soluble depending on the polysaccharide - protein ratio [36, 37]. Insoluble complexes are formed when the net charge on the complex is close to zero while soluble complexes are formed when the resulting complex has a high net charge. It has also been found that for certain systems electrostatic interaction can occur above the isoelectric point of the protein where both biopolymers carry a net negative charge. The interaction in this case is attributed to association between positively charged patches on the protein and the anionic groups on the polymer.

We have undertaken studies on the phase behaviour of gum Arabic (GA) - bovine serum albumin (BSA) systems by monitoring the turbidity and scattering intensity as the $\mathrm{pH}$ was gradually reduced in situ by the slow hydrolysis of glucono delta lactone [38]. For systems containing BSA:GA in ratios between $1: 1$ and $6: 1$, the turbidity (monitored by absorbance) was found to increase between $\mathrm{pH} \sim 4.7-5.2$ depending on the ratio (Figure 15a). However, the scattering intensity (monitored by light scattering) for the same systems increased at much higher $\mathrm{pH}(\sim \mathrm{pH} 5.5)$ (Figure 15b). This led to the conclusion that as the $\mathrm{pH}$ was reduced, initially soluble electrostatic complexes were formed but then as the $\mathrm{pH}$ was reduced further the complexes became insoluble. Using this approach it was possible to produce a phase diagram showing the soluble and insoluble regions as a function of $\mathrm{pH}$ and polysaccharide : protein ratio. Complexation was inhibited on addition of electrolyte and above a critical value $(\sim 50 \mathrm{mM} \mathrm{NaCl})$ it was completely prevented.

\section{Summary}


This paper provides a brief overview of the interactions that are known to occur in relatively dilute polysaccharide solutions which can provide an insight into the interactions that may occur in plant cell walls. The binding of cations to polysaccharides can be highly specific and often results in the association of the polysaccharide chains and the formation of a gel structure. Molecular association of different polysaccharide chains can occur particularly in the case where one of the polymers can adopt a helical conformation and the other is relatively stiff. Association is often through hydrogen bonding and a number of adjacent sugar residues are necessary in order to form a stable junction zone. Anionic polysaccharides can also interact with proteins and the complexes formed may be soluble or insoluble depending on the polysaccharide:protein ratio, the $\mathrm{pH}$ and the ionic strength.

\section{References}

1. Carpita, N.C.; Gibeaut, D.M. The Plant Journal 1993, 3, 1.

2. James, D.W.; Preiss, J.; Elbein, A.D.; Biosynthesis of polysaccharides In The Polysaccharides Vol 3 Aspinall, G.O. ed.; Academic Press Inc. Orlando, Florida, 1985 p107.

3. Christiaen, D.; Stadler, T.; Ondarza, M.; Verdus, M.C., Hydrobiologia, Ragan, M.A.; Bird, VC.J. (eds) Twelfth International Seaweed Symposium, Dr W. Junk Publishers Dordrecht Netherlands, 1987, 151/152, 139.

4. Lopes da Silva; Rao, M.A., Pectins: Structure, Functionality and Uses, In Food Polysaccharides and their applications Second Edition Stephen, A.M.; Phillips, G.O.; Williams, P.A. eds. CRC Press, Taylor and Francis Group, Boca Raton, FI USA, 2006, p 413. 
5. Voragen, A.G.J.; Pilnik, W.; Thibault, J.-F.; Axelos, M.A.V.; Renard, M.G.C., Pectin, In Food Polysaccharides and their applications. Stephen, A.M. ed. Marcel Dekker Inc Publishers, New York,1995 p 287

6. May, C.D. Pectins, In Handbook of Hydrocolloids, Phillips, G. O.; Williams, P. A. eds., Woodhead Publishing Ltd, Cambridge, UK 2000 p169.

7. Schols, H.A.; Ros, J.M.; Daas, P.J.H.; Bakx, E.J.; Voragen, A.G.J., In Gums and Stabilisers for the Food Indudtry 9, Williams, P.A.; Phillips, G.O. eds. Royal Society of Chemistry Special Publication No. 218, Cambridge, 1998, p3

8. Draget, K.I. Alginates, In Handbook of Hydrocolloids, Phillips, G. O.; Williams, P. A., eds., Woodhead Publishing Ltd, Cambridge, UK 2000 p 379.

9. Moe, S. T.; Draget, K. I.; Skjak-Braek, G.;Smidsrod, O., Alginates, In Food Polysaccharides and their applications, Second Edition, Stephen, A.M.; Phillips, G.O.; Williams, P.A., eds., CRC Press, Taylor and Francis Group, Boca Raton, FI USA, 2006, p 289.

10. Thom, D.; Grant, G.T.; Morris, E.R.; Rees, D.A., Carbohydr. Res. 198210029.

11. Grant, G.T.; Morris, E.R.; Rees, D.A.; Smith, P.J.C.; Thom, D., FEBS Lett. 1973, 32, 195.

12. Morris, E.R.; Rees, D.A.; Thom, D., Carbohydr. Res. 1978, 66, 145.

37. S. C. Kiong, Williams, P.A. and Young, N. W. G., Biomacromolecules, 6963 (2005).

13. Braccini, I.; Grasso, R.P.; Perez, S., Carbohydr. Res. 1999, 317, 119.

14. Braccini, I.; Perez, S., Biomacromolecules 2001, 2, 1089.

15. Emmerichs, N.; Wingender, J.; Flemming, H.-C.; Mayer, C., Int. J. Biol. Macromol. 2004, 34, 73

16. Chee Kiong Siew; Williams, P.A.; Young, N.W.G., Biomacromolecules 2005, 6, 963. 
17. Piculell, L., Gelling carrageenans, In Food Polysaccharides and their applications. Stephen, A.M.; Phillips, G.O.; Williams, P.A., eds., CRC Press, Taylor and Francis Group, Boca Raton, FI, USA, 2006, p 239.

18. Imeson, A., Carrageenan, In Handbook of Hydrocolloids, Phillips, G.O.; Williams, P.A., eds., Woodhead Publishing Ltd, Cambridge, England 2000, p 87

19. Millane, R.P.; Chandrasekaran, R.; Arnott,, S.; Dea, I.C.M., Carbohydr. Res. 1988, 182,1

20. Hermansson, A.-M.; Eriksson, E.; Jordansson, E., Carbohydr. Polymers, 1991, 16, 297.

21. Funami, T.; Hiroe, M.; Noda, S.; Asai, I.; Ikeda, S.; Nishinari, K., Food Hydrocolloids, 2007, 2, 617.

22. Tolstoguzov, V.B., Phase behaviour in mixed polysaccharide systems, In Food Polysaccharides and their applications. Stephen, A.M.; Phillips, G.O.; Williams, P.A., eds., CRC Press, Taylor and Francis Group, Boca Raton, FI, USA, 2006, p 589.

23. Williams, P.A.; Phillips, G.O., Interactions in mixed polysaccharide systems, In Food Polysaccharides, Stephen, A.M. ed. Marcel Dekker, New York, 1995, p 463.

24. Ahmad, F.B.; Williams, P.A., J. Agric. Fd Chem. 2001, 49, 1578

25. Williams, P.A.; Clegg, S.M.; Langdon, M.J.; Nishinari, K.; Piculell, L., Macromolecules 1993, 26, 5441

26. Williams, P.A.; Langdon, M.J., Biopolymers 1996, 38, 655

27. Nishinari, K.; Williams, P.A.; Phillips, G.O., Food Hydrocolloids, 1992, 6, 199

28. Wielinga, W., Galactomannans, In Handbook of Hydrocolloids, Phillips, G. O.; Williams, P.A. eds., Woodhead Publishers Ltd, Cambridge, UK 2000 p 137.

29. Dea, I.C.M.; MacKinnon, A.A.; Rees, D.A., J. Mol. Biol. 1972, 68, 153

30. Dea, I.C.M.; Clark, A.H.; McCleary, B.V., Carbohydr. Res. 1986, 147, 275 
31. Piculell, L.; Zhang, W.; Turquois, T.; Rochas, C.; Taraval, F.-R, Williams, P.A., Carbohydr. Res. 1994, 265, 281

32. Cooper, C.L.; Dubin, P.L.; Kayitmazer, A.B.; Turksen, S., Curr. Opin. In Colloid and Interface Sci. 2005, 10, 52

33. Schmitt, C. Sanchez, C.; Desbory-Banon, S.; Hardy, J., Crit. Rev. Food Sci. Nutr.1998, 38, 689

34. Sakamoto, T.; Bonnin, E.; Thibault, J.-F., Biochim. Biophys. Acta. 2003, 1621, 280

35. MacDougall,A.J.; Brett, G.M.; Morris, V.J.; Rigby, N.M.; Rideout, M.J.; Ring, S.G., Carbohydrate Res. 2001, 335115.

36. Noguchi, H., Biochim Biophys. Acta 1956, 22, 459

37. Weinbreck, F.; de Vries, R.; Schrooyen, P.; de Kruif,C.G., Biomacromolecules 2003, 4, 293

38. Weinbreck, F.;Tromp, R.H.; de Kruif, C.G. Biomacromolecules 2004, 5, 1437

39. Mahendran, T.; Williams, P.A.; Phillips, G.O.; Al-Assaf, S., Food and Food Ingredients, Journal of Japan, 2008, 213, 271. 


\section{Figure legends}

Figure 1 Hypothetical structure of apple pectin showing; I xylogalacturonan region, II region with arabinan side chains, III rhamnogalacturonan region making up the hairy region $(\mathrm{HR})$. SR is the smooth region (from reference 7).

Figure 2 Schematic representation of the disaccharide repeating units for acidic polysaccharides, (a) galacturonan, (b) glucuronan, (c) mannuronan and (d) guluronan with the torsion angles represented for galacturonan (from reference 13)

Figure 3 The 'egg-box' model in which calcium ions associated with uronic acids crosslink the polysaccharide chains (from reference 10)

Figure 4 Binding of $\mathrm{Mn}^{2+}$ ions to adjacent $\mathrm{MG}$ residues along the alginate chain (from reference 15)

Figure $5 \quad$ Binding curves for Mn 2+ ions with pectin and alginate with low and high mannuronate : guluronate ratio (from ref. 16).

Figure 6 Schematic representation of pectin and alginate interacting with divalent cations. (a) pectin or alginate chain, (b) interaction of a divalent ion with a single carboxyl group forming a monocomplex resulting in charge reversal, (c) interaction with the net positive charge with a carboxylate group on an adjacent polysaccharide chain, (d) crosslinking of the polysaccharide chains (from ref. 16). 
Figure $7 \quad$ Structure of the disaccharide repeat unit of carrageenans (a) lambda carrageenan where $\mathrm{R}$ is $\mathrm{H}$ or $\mathrm{SO}_{3}{ }^{-}$and (b) iota carrageenan where $\mathrm{R}_{1}$ and $\mathrm{R}_{2}$ are $\mathrm{SO}_{3}{ }^{-}$and kappa carrageenan where $\mathrm{R}_{1}$ is $\mathrm{H}$ and $\mathrm{R}_{2}$ is $\mathrm{SO}_{3}{ }^{-}$

Figure 8 Schematic representation of the coil - helix transition of carrageenan and helix aggregation.

Figure 9 AFM images of kappa carrageenan gels formed in the presence of (a) potassium, (b) sodium and (c) calcium ions (from ref 21).

Figure 10 Schematic illustrating the types of behaviour that can occur on mixing polymers in aqueous solution.

Figure 11 Photograph illustrating phase separation occurring in aqueous mixtures of gelatinised sago starch and dextran.

Figure 12 Phase diagram showing the phase boundary for aqueous mixtures of sago starch and guar / locust bean gum (from reference 23).

Figure 13 DSC cooling curves for kappa carrageenan / konjac mannan mixtures in the presence of $50 \mathrm{mM} \mathrm{KCl}$. A) $0.1 / 0.5$, B) $0.2 / 0.4$, C) $0.3 / 0.3$, D) 0.4/0.2, E) $0.45 / 0.15, F)$ 0.5/0.1 and G) $0.6 / 0$ (from reference 24 ).

Figure 14 Schematic illustration of the interaction of kappa carrageenan and locust bean gum at low carrageenan content (from reference 25).

Figure 15a Absorbance of mixtures at varying BSA:GA ratio $(0.5 \% \mathrm{GA})$ as a function of $\mathrm{pH}$ (from reference 38).

Figure 15b Scattering intensity for BSA:GA (0.5\% GA) systems at varying mixing ratio (1:1 to $20: 1$ ) as a function of $\mathrm{pH}$ ( from reference 38 ). 
Figure 1

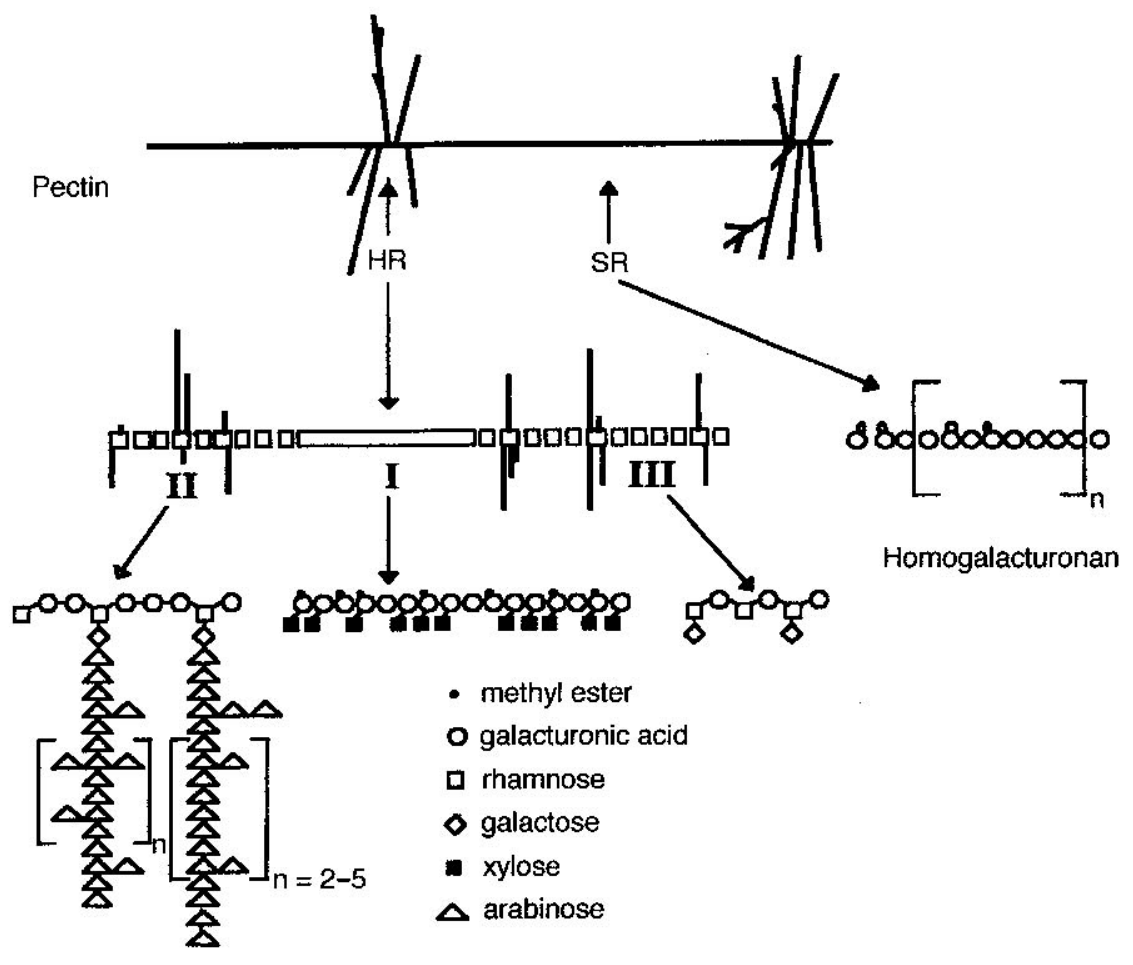


Figure 2
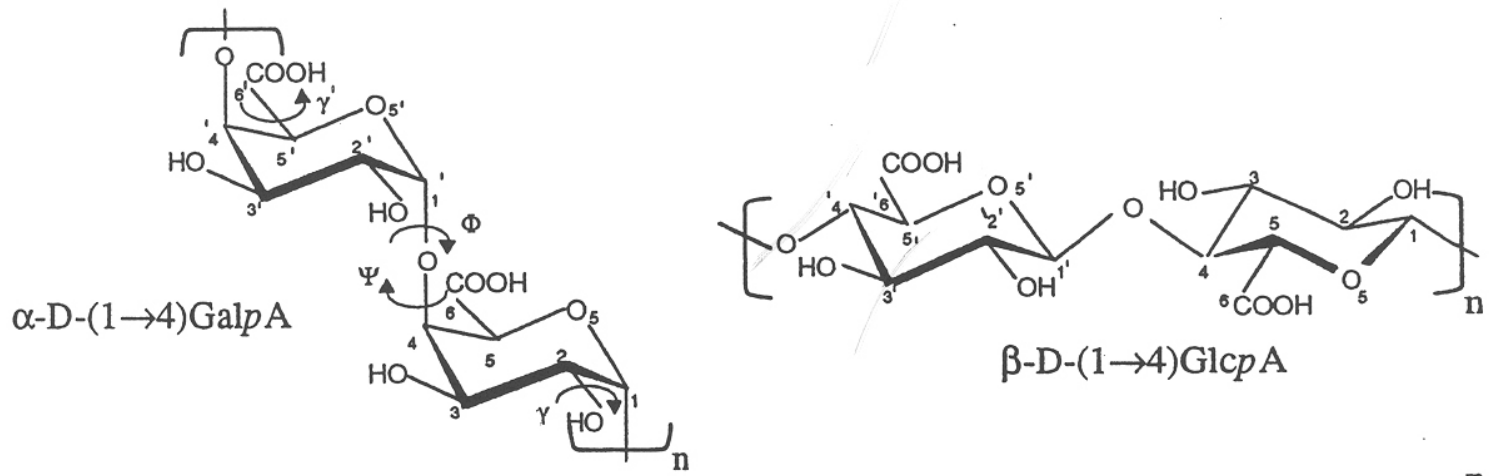

$\beta$-D-(1 $\rightarrow 4)$ GlcpA
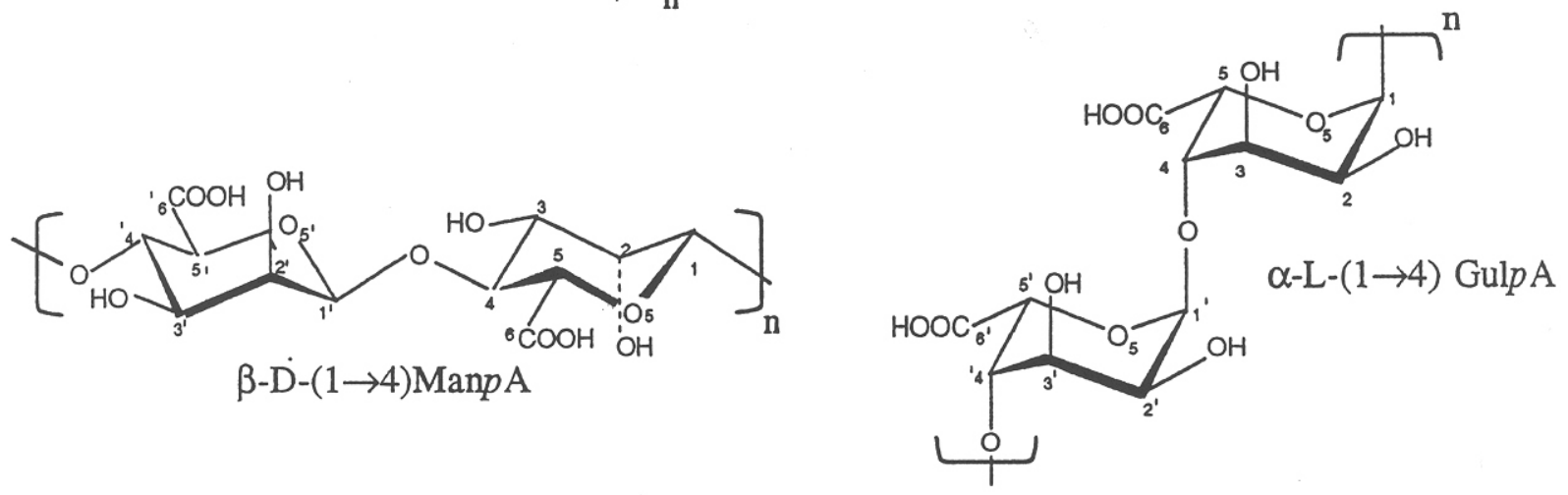

$\beta$-D-(1 $\rightarrow 4)$ Manp A 
Figure 3

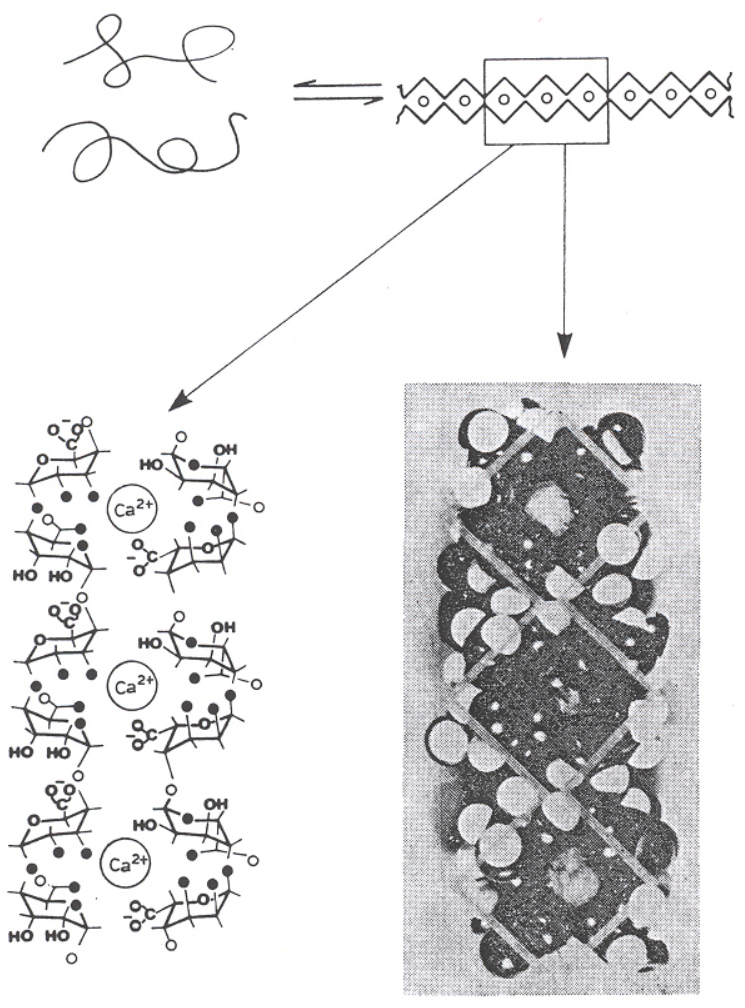


Figure 4

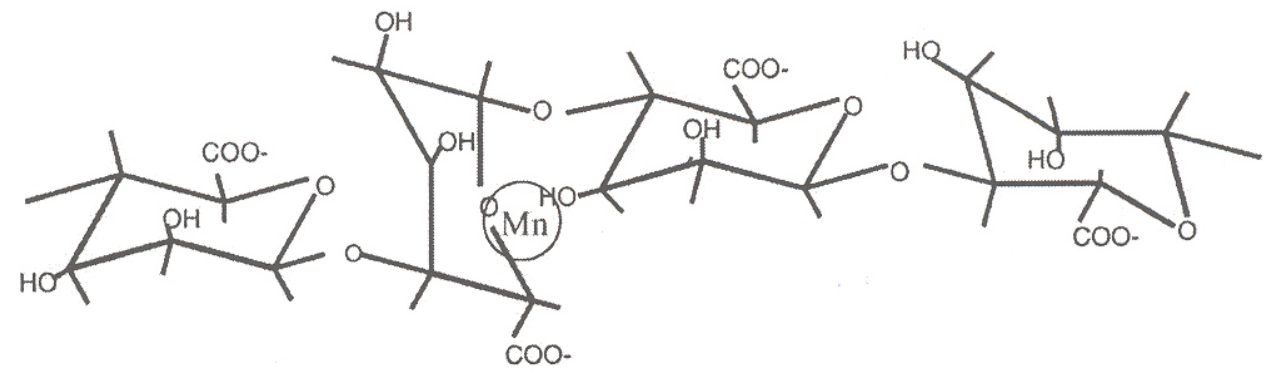


Figure 5

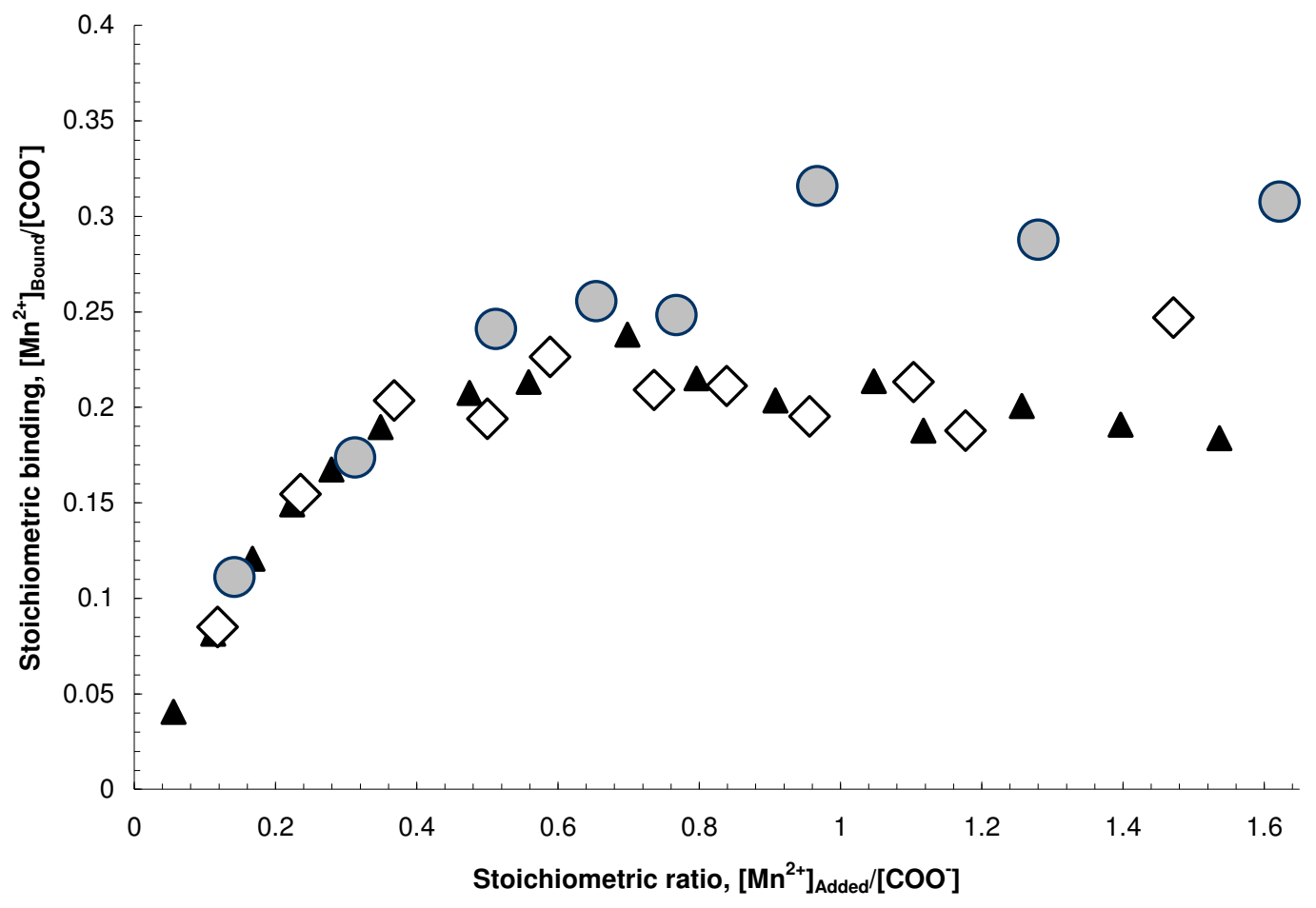

$\Delta$ Alginate - High M:G $\diamond$ Alginate - Low M:G O Pectin 
Figure 6
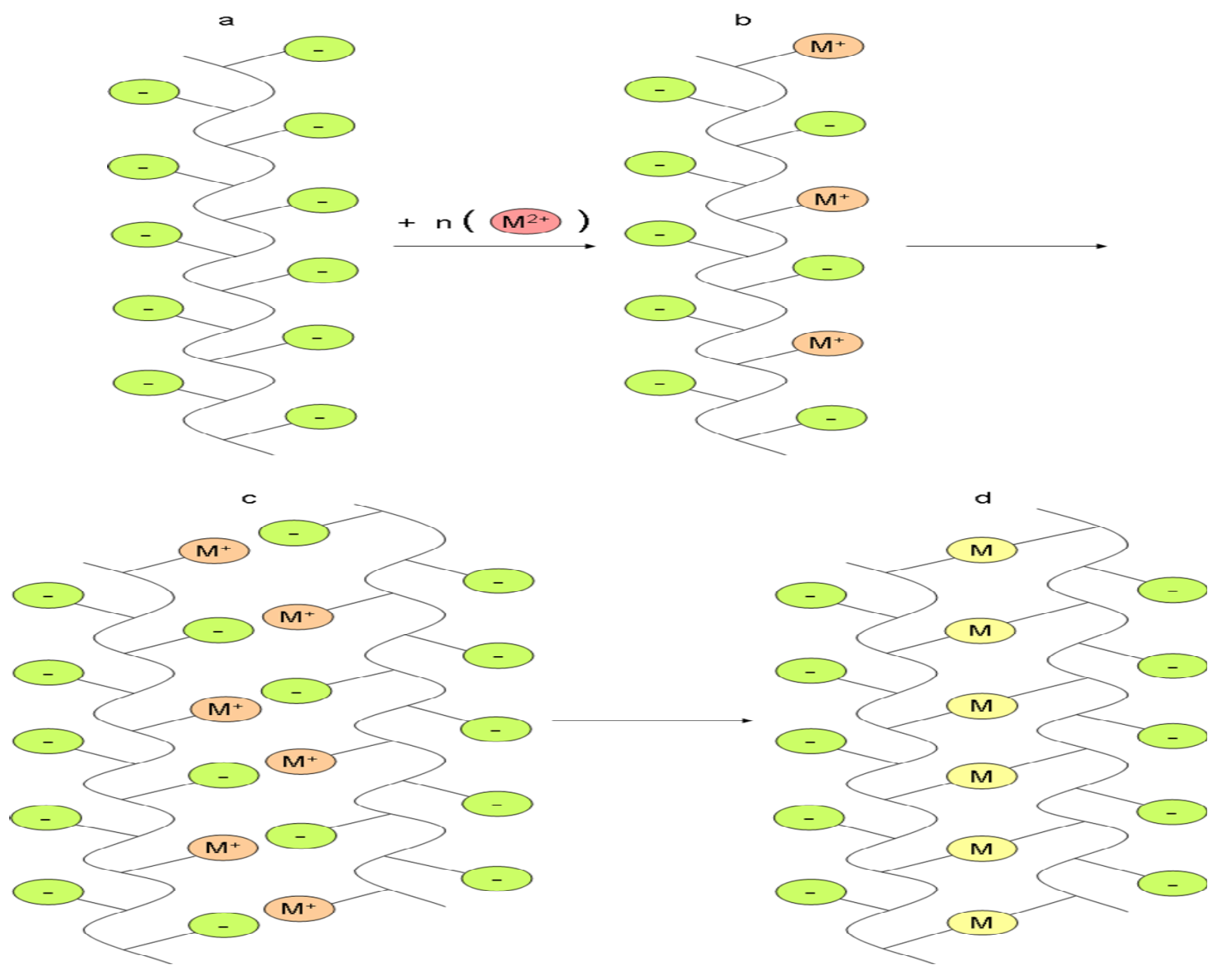
Figure 7

(a)

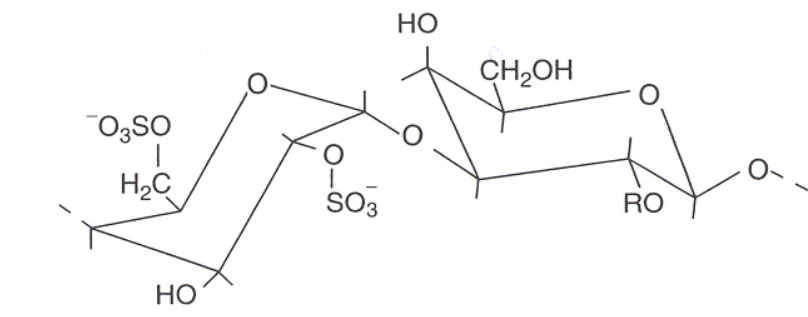

(b)

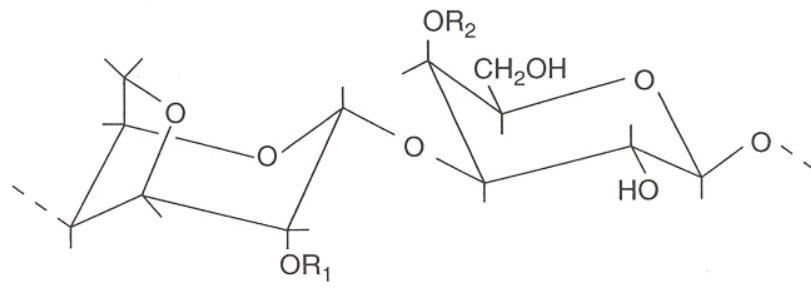


Figure 8

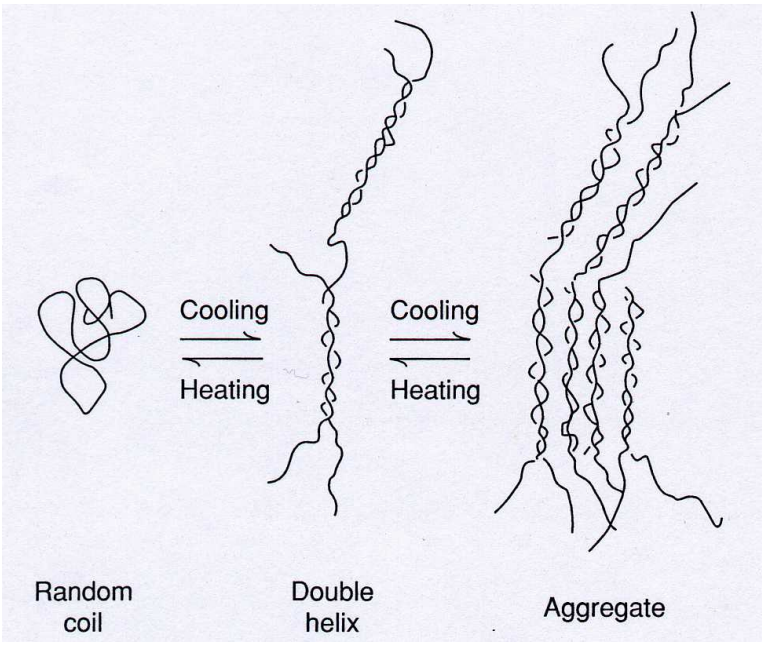


Figure 9

(a)

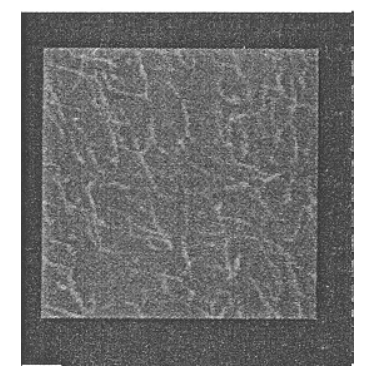

(b)

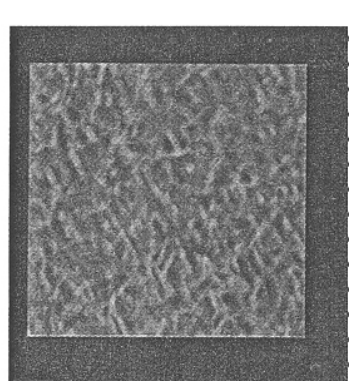

(c)

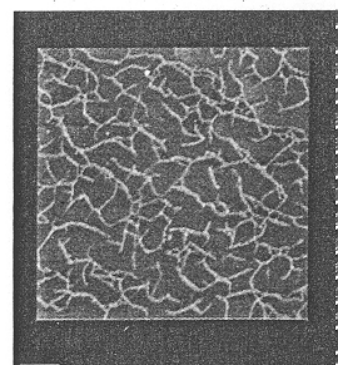


Figure 10 


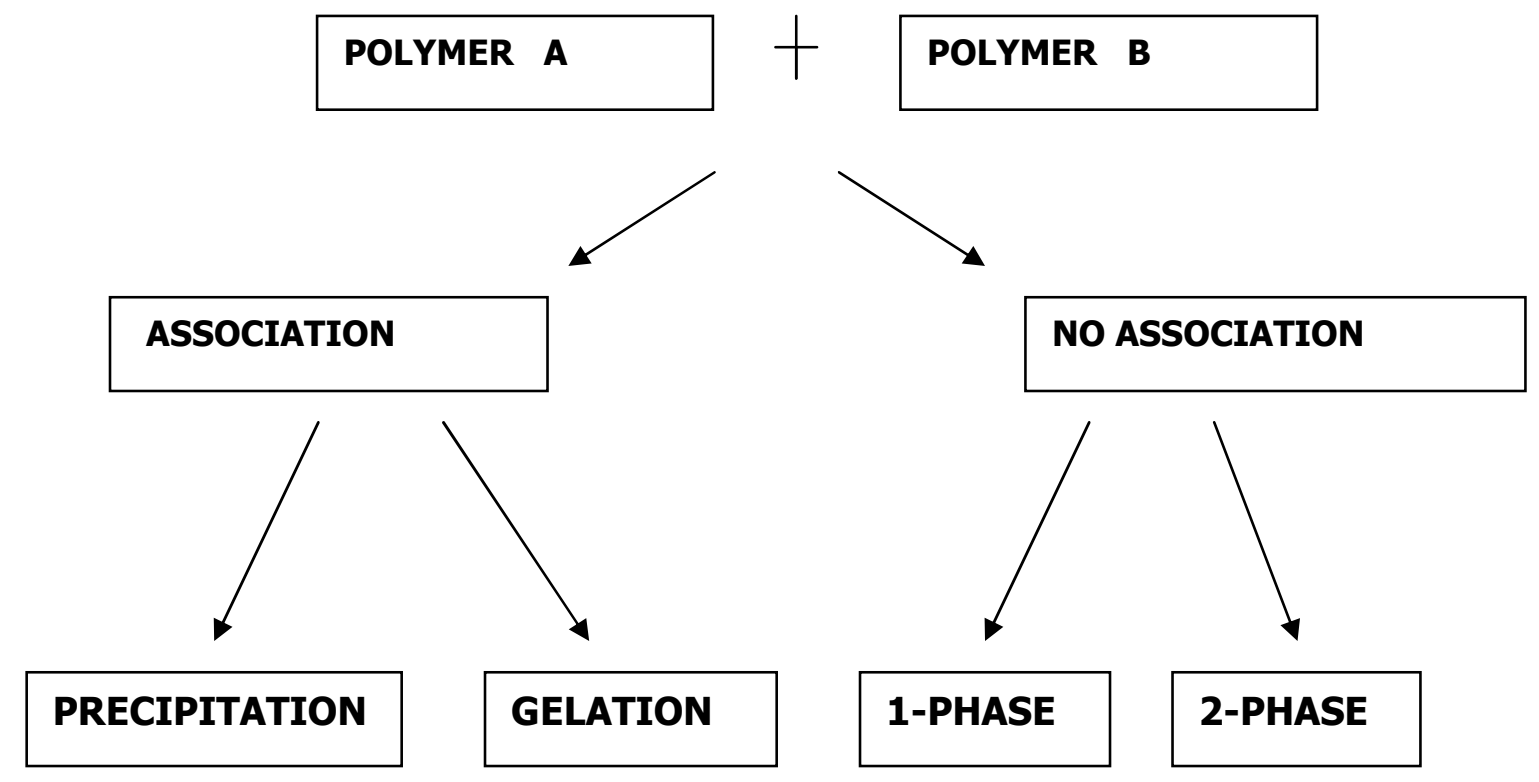

Figure 11 


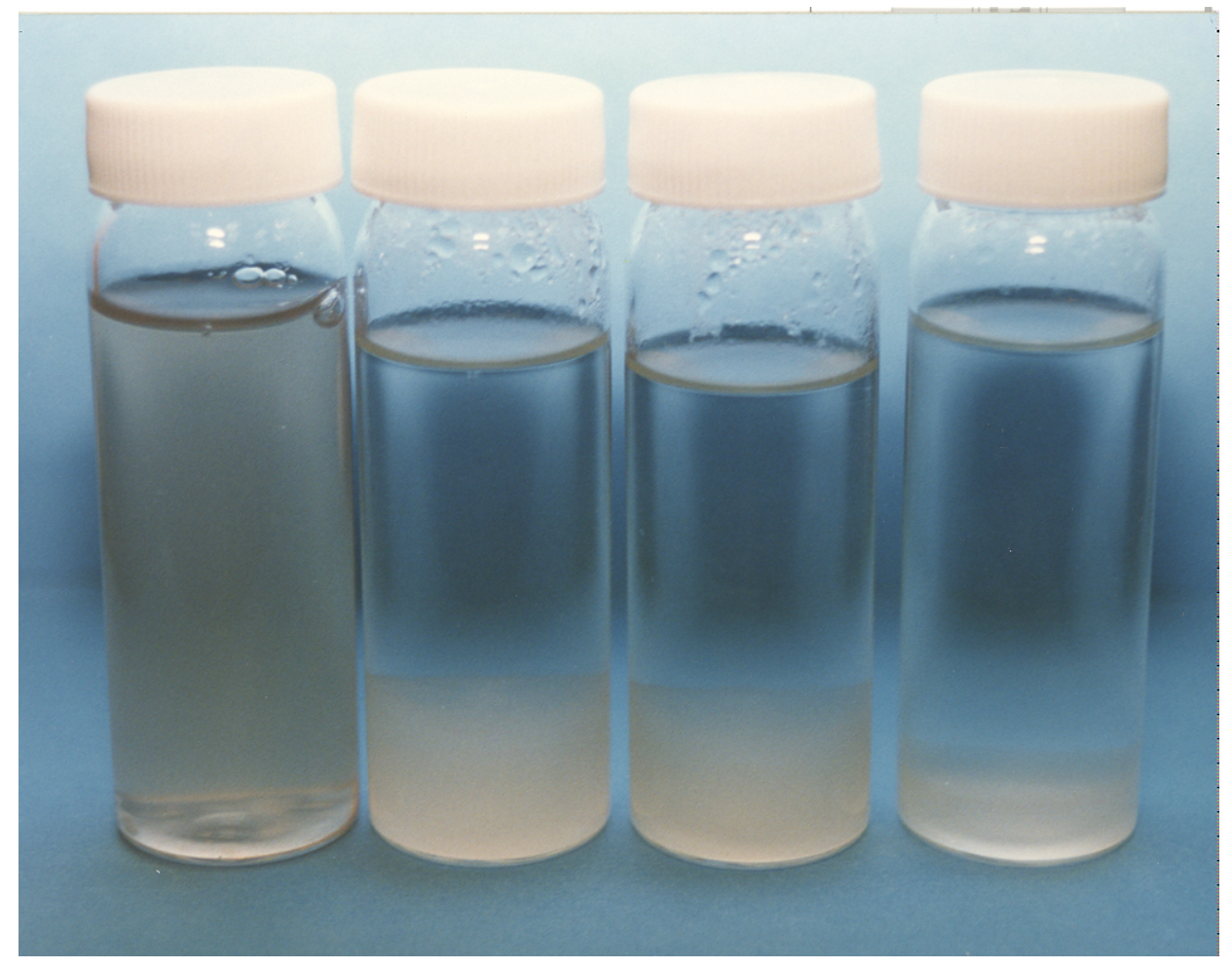

Figure 12 


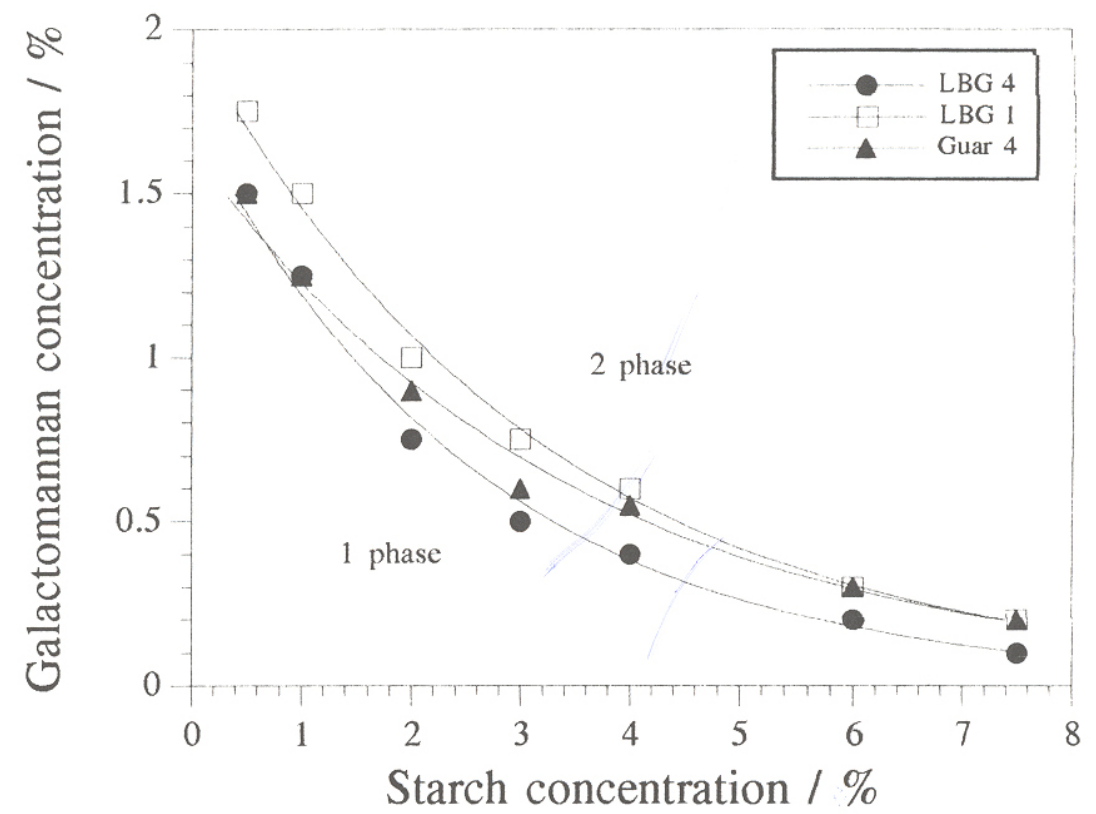

Figure 13 


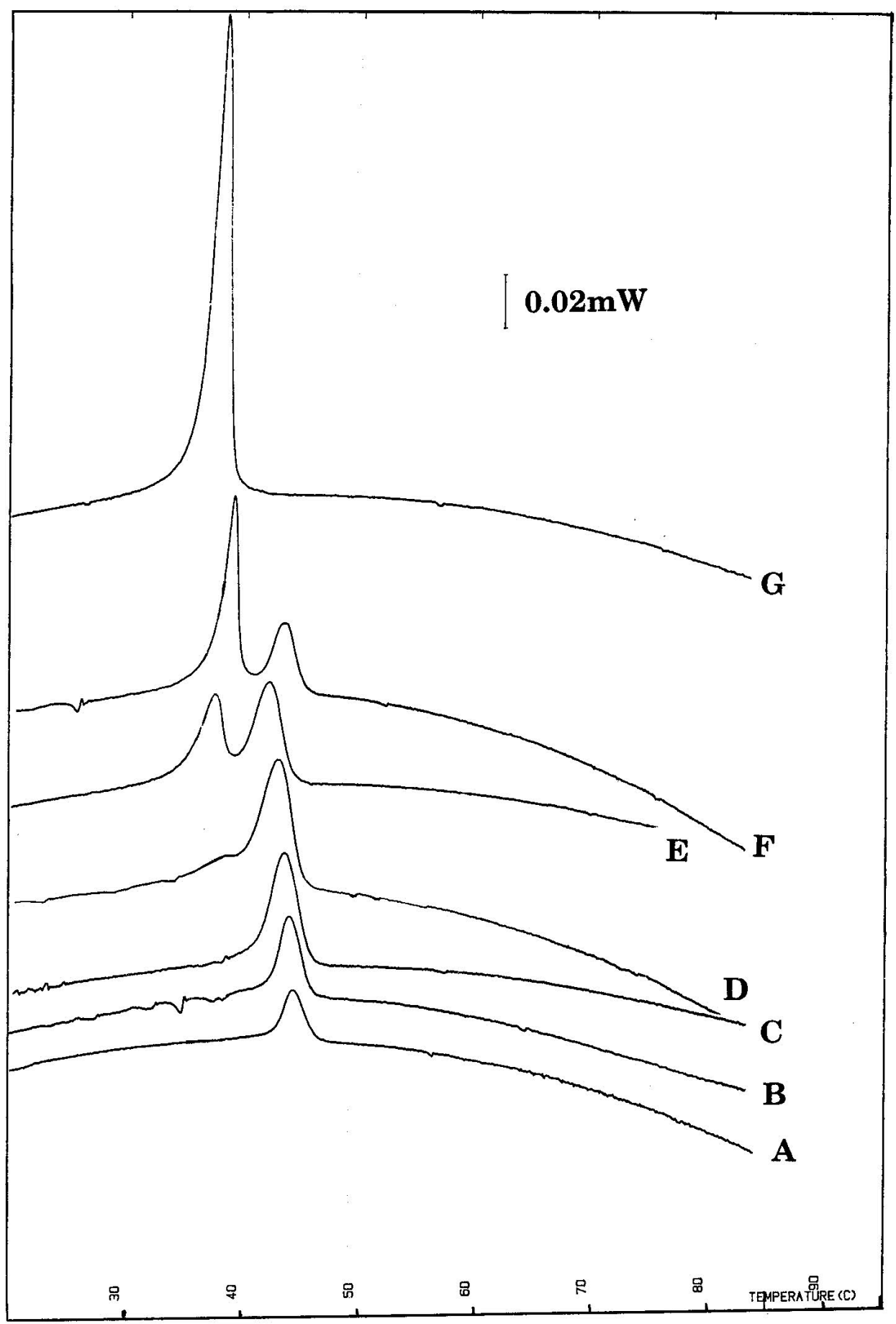

Figure 14 


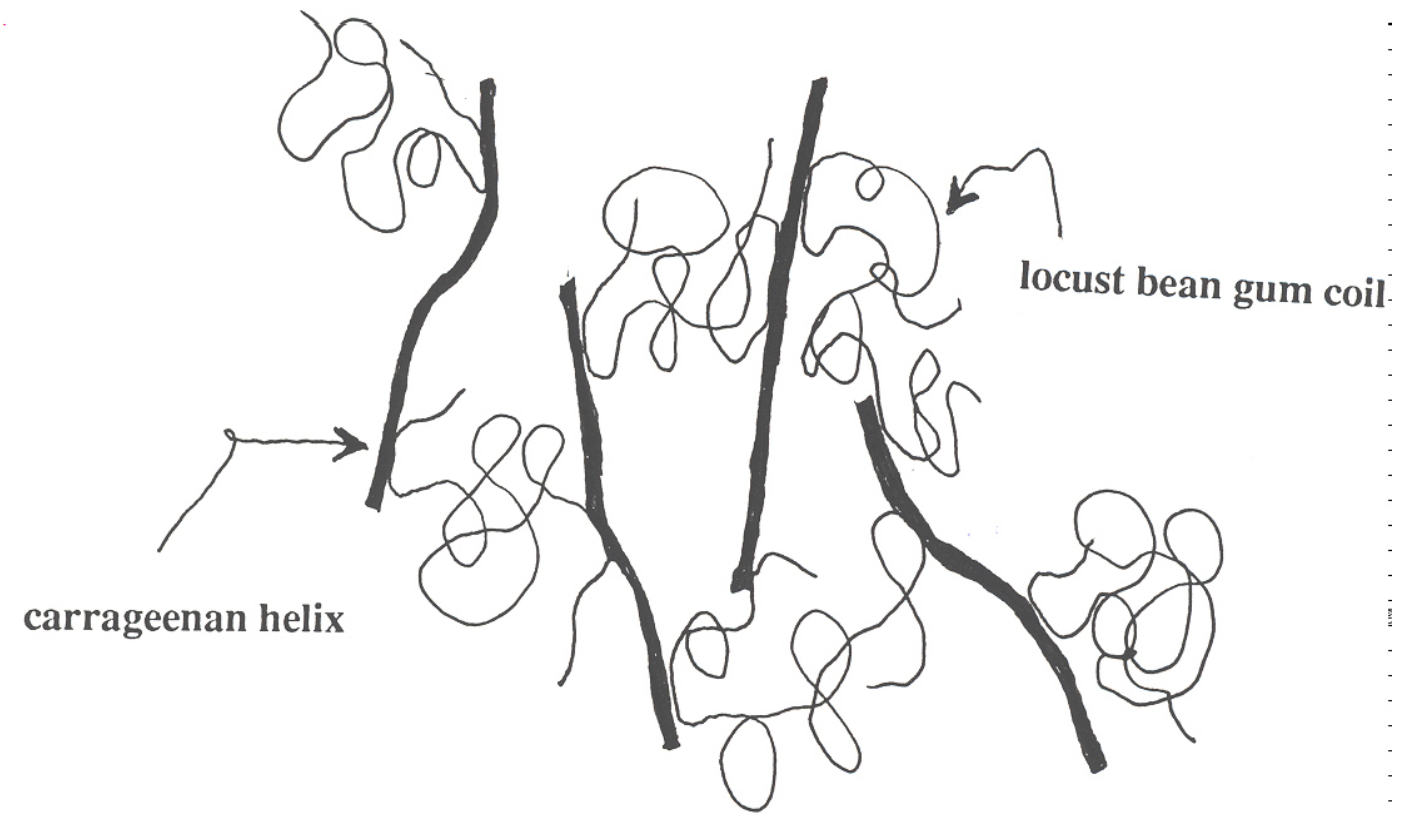


Figure 15a

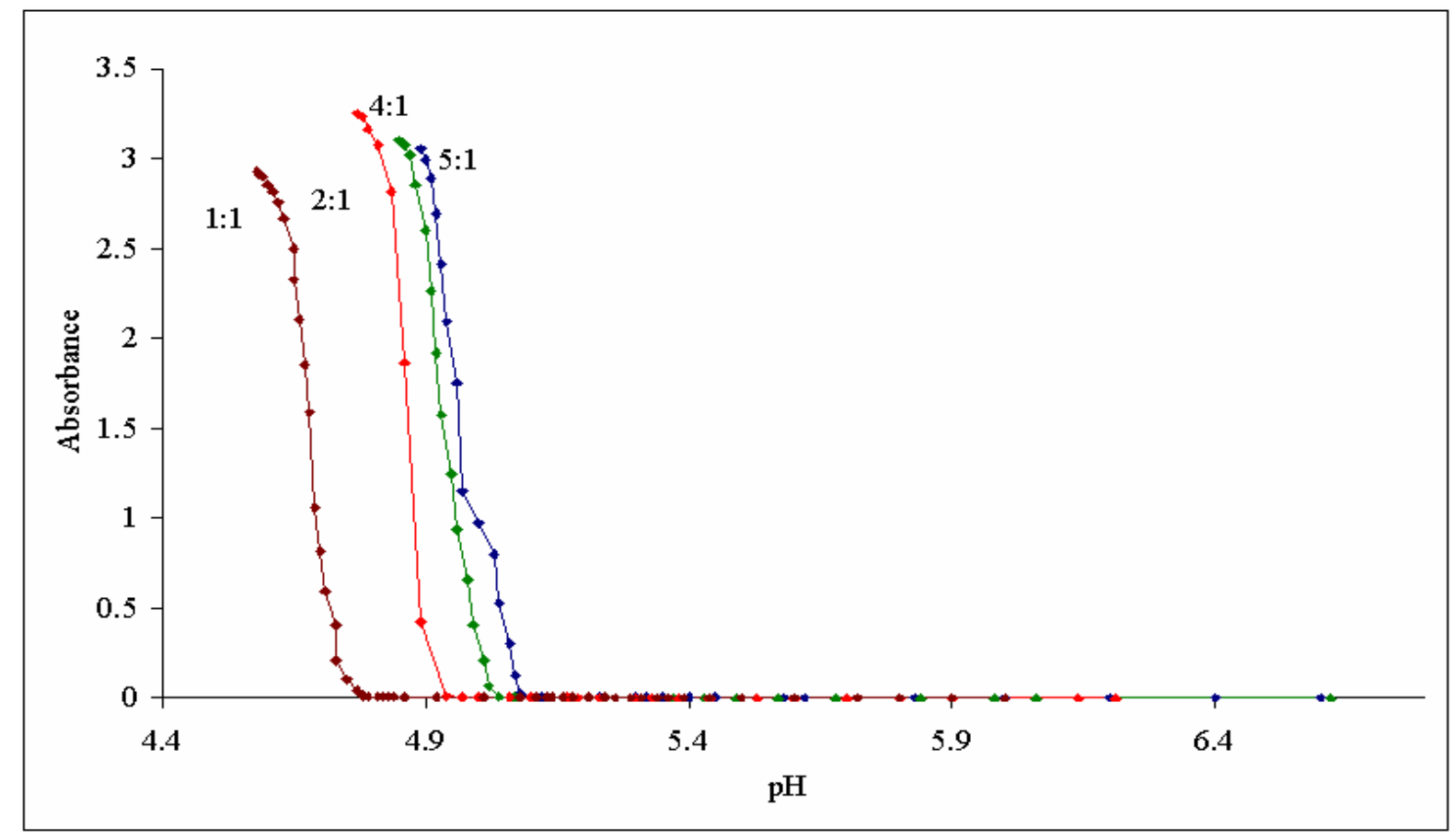


Figure 15b

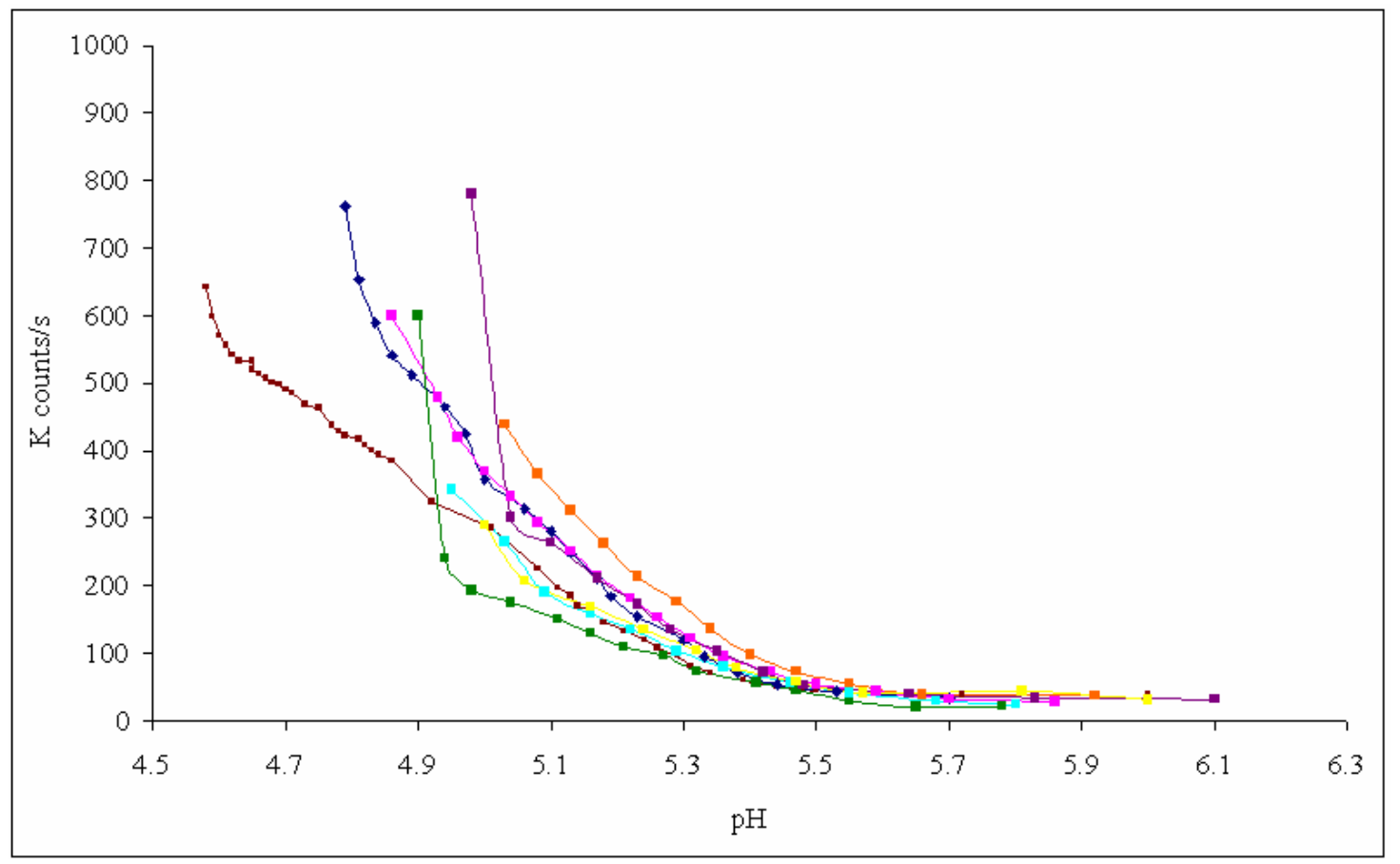

